\title{
Toxic Effects of the Most Prevalent Addicting Drugs among Some Egyptian Secondary School Students on the Reproductive System: Clinical and Experimental Study
}

\author{
Omaima I. Abdel Hamid, Yara M. El-fakharany ${ }^{1}$ and Amira E. Abdel-Salam² \\ ${ }^{1}$ Forensic Medicine and Clinical Toxicology Department. \\ ${ }^{2}$ Community Medicine Department, Faculty of Medicine.
}

Faculty of Medicine, Zagazig University, Al sharqia, Egypt.

\begin{abstract}
Substance abuse among adolescents is an increasing social and medical problem in Egypt especially with lacking of information regarding prevalence and types of abused drugs. Drug abuse in this critical period of testicular development seems to affect fertility. The objectives of this work was to study the prevalence of addicting drugs among adolescent males in secondary public schools and to examine the insult of most prevalent drugs on the fertility of adolescent male albino rats. Participated students were subjected to a structured questionnaire and urine screening for drugs of abuse. The overall prevalence of abused drugs was $13.6 \%$, tramadol was the most (50.5\%) followed by cannabis (14.6\%). Animal equivalent doses of tramadol \& hashish were given orally to 60 male albino rats for 4 months to test their toxic effects on the reproductive system. Significant reduction in testicular weight, relative testicular weight, luteinizing hormone (LH), testosterone in tramadol, hashish groups with the maximum decrease in combined tramadol+hashish group. Degenerative changes with sloughing \&disorganization of epithelial cells were detected in H\&E stained testicular sections in tramadol \& hashish groups, while in the combined group the degeneration was severe with vaculation, interstitial fibrosis, hyalinization and no aggregated sperms in the lumen. It was concluded that the most prevalent abused drugs among adolescents were tramadol, hashish or combination. These drugs have a structural \& functional disruption on the reproductive system in adolescent period.
\end{abstract}

Keywords Testes, Tramadol, Hashish, Adolescence, Egypt.

\section{Introduction}

A dolescent substance abuse continues to be a significant social problem. It is well established that regular use of substances during the teenage years increases the likelihood of developing a substance use disorder that refers to the use of one or more substances leading to a clinically significant impairment or distress (Miller et al., 2007).

In the Eastern Mediterranean Region, drug use disorders are common and accounting for a loss of 4 disability-adjusted life years (DALYs) and 9 deaths per 1000 population, compared with the loss of 2 DALYs and 4 deaths per 1000 population globally (Kronfol, 2012). In developing countries like Egypt, there is a lack of information regarding the prevalence of substance abuse (Nabil et al., 2015).

Substance abuse in adolescents is associated with a number of adverse consequences, such as increased medical and mental health problems, absenteeism, and disciplinary problems in school. In some cases, substance abuse can lead to unintentional injury and even death (Knight et al., 2007).

One of the important complications of substance use disorder is infertility; Recreational use of illicit drugs is an important consideration when assessing the etiology of male infertility (Fronczak et al., 2012). 
Hamdi et al., (2013) found that the 15-19 age group showed the highest onset of substance use in Egypt. So it appears that use of these illicit substances has been often during critical periods of testicular development. There are several notable limitations of the present understanding of the effects of illicit drugs on male fertility, including the assessment of the impact of multiple illicit drug interactions on fertility.

\section{Aim of the work}

The present work was conducted to study the prevalence of addicting drugs among adolescent males in secondary public schools and to examine the insult of most prevalent drugs on the fertility of male albino rats.

\section{Methodology}

The work passed into two phases : clinical and experimental studies

\section{Ethical considerations:}

Regarding the clinical study: Permission from Province of Education in Zagazig city was obtained to carry out the study. Explaining the aim and procedures of the study and ensuring the confidentiality of information were conducted clearly for subjects.

Regarding Experimental study: The study was conducted after the approval of the Institutional Review Board on animal research at Faculty of Medicine, Zagazig University, Egypt and in accordance with the international guidelines for animal research to insure (3Rs): replacement of the use of animals with alternative techniques if possible, reduction of the number of animals used to a minimum and refinement of the experimental procedures carried out to make sure animals suffer as little as possible. This was done through subjecting animals before commencing experimentation, to 10 days of passive preliminary period to adapt to their new environment, to ascertain physical wellbeing and to exclude diseased animals. Food was offered in equal amounts to all rats, water was offered in separate clean containers. Animals were anaesthetized by ether before scarification to minimize pain.

I-Clinical study

A cross-sectional study in four secondary schools in Zagazig district, Sharkia Governorate, Egypt during the studying year 2015-2016 to determine the prevalence of drug abuse, the most common abused drugs and its relation to the socio-demographic data of the students.

Sampling and sample size:

Sample size:

The sample size was calculated using Epi-info program, assuming the prevalence of drug abuse 9.6\% (Hamdi et al., 2013), power $80 \%$ at $95 \%$ confidence level. A sample of 865 students was calculated; 576 students at urban schools and 289 at rural schools.
Sample selection:

Zagazig district is divided according to Ministry of Education into 2 sectors (East and West) each sector contains rural and urban areas. Sampling was carried out using multistage cluster random sampling. East sector was randomly selected; this sector contains a total number of male students 20000 in the secondary schools.

The sampling frame included all secondary public schools within the east sector. Some schools within this sector were randomly selected representing both urban and rural areas with proportional allocation of the students' number. Two urban and two rural schools were randomly selected. Classes within each school were also randomly selected; all students in the selected classes were included in the study.

1-Questionnaire: students who agreed to participate in the study answered a structured questionnaire that gathered information about their socio-demographic characteristics, types of substances being abused, their doses, duration of abuse and frequency of their use (Appendix I).

2-Urine screening for drugs of abuse:

- $\quad$ Urine samples $(10 \mathrm{ml})$ were collected from each student involved in the study in sterile containers for detection of drugs of abuse using accurate (rapid card test) immunoassay kits manufactured by Assure Tech (Hangzhou) Co., Ltd for genelab and made in P.R.C. with lot numbers: morphine (Lot: 306002), Cannabis (Lot: 306001), tramadol (Lot: 306004) and benzodiazepines (lot:306003).

\section{Inclusion criteria:}

Students who admitted they're abusing drugs by questionnaire and showed +ve urine analysis for drugs of abuse were included in the statistical analysis of the study.

\section{Exclusion criteria:}

Students who admitted that they're abusing drugs by questionnaire but showed -ve urine screening tests were excluded $(n=20)$. Also, students who denied abusing drugs by questionnaire but showed +ve urine screening test were excluded $(\mathrm{n}=87)$.

\section{II-Experimental study}

An experimental study was done to investigate the toxic effect of tramadol, hashish; the most prevalent abused drugs according to the clinical study; on the reproductive system of male albino rats.

Sixty male albino rats weighing $150-200$ g were included in the study and obtained from the animal house of Faculty of Medicine, Zagazig University. The age of the rats (55-65days) were selected to be equivalent to the average age of subjects included in the clinical study according to (Quinn, 2005 ; Sengupta, 2012). They 
reported that the age of puberty in rats (6wks) is equivalent to 12.5 years in human and after that comes the adolescent period where every 10.5 days in rats equals 1 year in human.

The rats were divided into five groups

- Group I (Negative control): 10 rats received water and diet to measure the basic parameters of the experimental animals.

- Group II (Positive control group): 20 rats subdivided equally into:

1- Subgroup IIA (Normal saline): each rat received 1 $\mathrm{ml}$ of normal saline $0.9 \%$ (solvent of tramadol) once daily by oral gavage.

2- Subgroup IIB (Olive oil): each rat received $1 \mathrm{ml}$ of olive oil (solvent of hashish) [7] once daily by oral gavage.

- Group III (Tramadol): 10 rats, each rat received 42 $\mathrm{mg} / \mathrm{kg} / \mathrm{day}$ tramadol capsule (100 mg tramadol hydrochloride) obtained from October Pharma S.A.E, Egypt (under license of German Grunenthal Company) dissolved in normal saline $0.9 \%$ by oral gavage. This dose is equivalent to the human dosing regimen of $400 \mathrm{mg} / \mathrm{day}$; the most prevalent dose used by students included in the clinical study. It was calculated using body surface area conversion equation \{animal dose $(\mathrm{mg} / \mathrm{kg})=$ human equivalent dose $(\mathrm{mg} / \mathrm{kg}) \times 6.2)$, assuming that an adolescent person weighs $60 \mathrm{~kg}$ (Reagan-Shaw et al., 2008).

- Group IV (Hashish): 10 rats, each rat received 103 $\mathrm{mg} / \mathrm{kg} /$ day hashish obtained, after taking permission, from Ministry of Justice dissolved in olive oil (Miras et al., 1971) by oral gavage. This dose is equivalent to the human dosing regimen of $1 \mathrm{~g} /$ day based on body surface area conversion (Reagan-Shaw et al., 2008). The previous dose of hashish represents most prevalent dose used by students included in the study.

- Group V (Tramadol+Hashish): 10 rats, each rat received hashish and tramadol concurrently in the same doses and duration as group III and IV

The duration of drugs administration was four months. At the end of the experimental period, all rats' weights were recorded.

Twenty-four hours after the end of the study, venous blood samples were obtained from the retroorbital plexus of anaesthetized animals as described by Sharma et al., (2014). Blood samples were centrifuged to separate the serum and maintained at $\left(-20^{\circ} \mathrm{C}\right)$ to be used for estimation of serum levels of luteinizing hormone (LH) and testosterone.

LH was measured by competitive inhibition enzyme immunoassay technique using Rat ELISA kit with Cat. No. (KT-21064) from Kamaya Biomedical Company. Testosterone was measured by solid phase enzyme-linked immunosorbent assay (ELISA), based on the principle of competitive binding using Mouse/Rat Testosterone ELISA kit with Cat. No. (55-TESMS-E01) from Alpco Diagnostics.
After blood samples collection, rats were sacrificed and both testes of each rat were excised, grossly inspected and weighed. The mean weight of both testes was estimated and then calculated in relation to the body weight (relative testes weight) for all studied groups.

The testis of one side for each rat was fixed in Bouin's solution then stained by Hematoxylin and Eosin stains according to method described by Bancroft and Gamble (2002).

\section{Results}

Among the subjects of the study ( $\mathrm{n}=758$ ); drug abusers were $13.6 \%$. Table (1) illustrates that the average age of the studied group was 16 years; drug abuse was significantly higher among urban residents and those belonging to high and Low social classes.

The most commonly used drugs among drug abuse students were tramadol (50.5\%), combined tramadol and hashish (20.4\%) and hashish 14.6\%. Eighty-nine students (86.4\%) abused drugs in a regular pattern. The duration of abuse was less than one year in 45 subjects $(43.6 \%)$ while 58 students (56.4\%) abused drugs for one year or more (Table 2).

Statistical comparison among group I (-ve control), group II A (normal saline) and group IIB (olive oil) as regard mean values of body weight, testicular weight, relative testicular weight, $\mathrm{LH}$ and testosterone revealed no significant differences ( $>0.05$ ), so we use negative control group as a standard reference for comparison with other treated groups.

Statistical comparison among group I (-ve control), group III (tramadol), group IV (hashish) and group V (tramadol+hashish) regarding mean values of body weight, testicular weight, relative testicular weight, LH and testosterone revealed significant differences $(p<0.001)$ by ANOVA test (table 3$)$.

Regarding the mean values of body weight; there was no statistically significant difference between ve control, hashish and tramadol+hashish groups $(\mathbf{p}>\mathbf{0 . 0 5})$, while there was a significant decrease in the mean body weight of rats of tramadol group when compared with - ve control and hashish group $(\mathbf{p}<\mathbf{0 . 0 0 1})$. The mean values of the body weight of rats of tramadol+hashish group showed a significant increase when compared with those of tramadol group and a significant decrease on comparison with those of hashish group ( $\mathbf{p}<\mathbf{0 . 0 5})$ by LSD test (table 3$)$.

The mean values of rats' testicular weight of tramadol group showed non-significant differences when compared with those of -ve control or hashish groups $(p>0.05)$, while there was a significant decrease in hashish group when compared with -ve control group $(p<0.05)$. Also, significant decreases in tramadol+hashish 
group when compared with other groups were detected $(\mathrm{p}<0.001)$ (table 3$)$.

As regard the mean values of rats' relative testicular weight; there was a non-significant decrease in tramadol group when compared with -ve control $(\mathrm{p}>0.05)$ and significant increase when compared with hashish and tramadol+hashish groups $(\mathrm{p}<0.001)$. Also, significant decreases hashish and tramadol+hashish groups were detected when compared with -ve control group $(\mathrm{p}<0.001)$, while there was non-significant difference on comparison between hashish and tramadol+hashish groups ( $\mathrm{p}>0.05)$ (table 3$)$.

The mean values of serum LH of tramadol group rats are significantly lower than those of -ve control group $(\mathrm{p}<0.001)$, while they are non-significantly different from those of hashish group. A significant decrease in serum LH levels in hashish group when compared with -ve control group was detected $(\mathrm{p}<0.001)$. There were significant decreases in tramadol+hashish group when compared with -ve control $(\mathrm{p}<0.05)$, tramadol $(\mathrm{p}<0.001)$ and hashish groups $(\mathrm{p}<0.001)$ (table 3$)$

There were significant decreases in the mean values of serum testosterone levels in tramadol, hashish and tramadol+hashish groups when compared with -ve control group $(\mathrm{p}<0.001)$. Also, significant decreases in tramadol+hashish group were detected when compared with those of tramadol and hashish groups $(\mathrm{p}<0.05)$. No significant difference between tramadol and hashish groups ( $\mathrm{p}>0.05)$ (table 3$)$.

\section{Histologic testicular examination}

1- Macroscopic examination:

Gross inspection of the testes of control (-ve, +ve

\&olive oil), tramadol and hashish groups revealed normal appearance with no significant changes in size, any cystic changes or abnormal masses. Cut sections were normal. While testes of tramadol+hashish group showed obvious decrease in size

2- Light microscopic examination :

Examination of H\&E testicular stained sections from rats of control groups (-ve, +ve, olive oil) showed normal seminiphrous tubules lined by intact stratified germinal epithelium with patent lumen and aggregated sperms. Seminiphrous tubules separated by narrow interstitial spaces containing groups of interstitial cells \&blood vessels (fig 1)

Stained testes sections from tramadol group showed moderate degenerative changes in seminiphrous tubules with sloughing of some epithelial cells in lumen. The rest of the epithelial cells are well organized (fig 2). In hashish group, the detected changes were moderate degeneration in some seminiphrous tubules with pyknotic nuclei, disorganization and sloughing of epithelial cells. Other tubules show normal structure with intact basal lamina and well organized epithelial cells and aggregated sperms (fig 3).

Testicular sections from tramadol+hashish group showed severe degenerative seminiphrous tubules with pyknotic nuclei, disorganization, vaculation and separation of epithelial cells with Hyalinization between and inside seminiphrous tubules, interstitial fibrosis and separation of the basal lamina. No aggregated sperms were seen in the lumen and some cells showed karyolysis (fig 4, 5). The degenerative changes detected in the testes of treated rats were semi-quantitatively graded according to the percentage of affected tubules as described by Lanning et al., (2002) (table 4).

Table (1): Statistical difference between drug abusers and non-abusers regarding socio-demographic criteria by Chi square:

\begin{tabular}{|c|c|c|c|c|c|}
\hline Socio-demographic variables & Drug abusers & Non-abusers & \multirow{2}{*}{ Total } & \multirow{2}{*}{$\mathrm{X}^{2}$} & \multirow{2}{*}{$\mathbf{P}$} \\
\hline Age & \multicolumn{2}{|c|}{$16 \pm 1.5$} & & & \\
\hline $\begin{array}{l}\text { Residence: } \\
\text { Urban } \\
\text { Rural } \\
\end{array}$ & $\begin{array}{l}80(77.6) \\
23(22.4)\end{array}$ & $\begin{array}{l}394(60.1) \\
261(39.9)\end{array}$ & $\begin{array}{l}474 \\
284 \\
\end{array}$ & 11.7 & $0.001^{*}$ \\
\hline $\begin{array}{l}\text { Social class: } \\
\text { Low } \\
\text { Moderate } \\
\text { high }\end{array}$ & $\begin{array}{l}43(41.7) \\
14(13.6) \\
46(44.7)\end{array}$ & $\begin{array}{l}213(32.5) \\
189(28.8) \\
253(38.7)\end{array}$ & $\begin{array}{l}256 \\
203 \\
299\end{array}$ & 10.8 & $0.004 *$ \\
\hline Total & $103(13.6 \%)$ & 655 (86.4\%) & 758 & & \\
\hline
\end{tabular}

*: Significant $(p<0.05)$ 
Table (2): Distribution of students according to types, dose, frequency\& duration of abuse substances:

\begin{tabular}{|l|r|r|}
\hline Pattern of drug abuse & n & \multicolumn{1}{|c|}{$\%$} \\
\hline Overall prevalence & 103 & $\mathbf{1 3 . 6}$ \\
Types of drugs: & 52 & $\mathbf{5 0 . 5}$ \\
Tramadol & 15 & 14.6 \\
Cannabis (hashish) & 0 & 0 \\
Morphine & 6 & 5.8 \\
Benzodiazepines & 21 & 20.4 \\
Tramadol + cannabis & 9 & 8.7 \\
Tramadol + Benzodiazepines & & \\
\hline Dose of most frequent abused drugs & $\mathbf{5 2}$ & \\
Tramadol (tablet 200mg) & 10 & 19.3 \\
1/2 tablet/day & 6 & 11.5 \\
1 tablet /day & 30 & 57.7 \\
2 tablets /day & 6 & 11.5 \\
More than 2 /day & $\mathbf{1 5}$ & \\
Cannabis (kersh =4gm) & 4 & 26.7 \\
1/8kersh hashish/day & 11 & 73.3 \\
1/4 kersh hashish/day & 0 & \\
1/2 kersh hashish/day & 0 & \\
1 kersh hashish /day & & \\
\hline Frequency of abuse: & 89 & $\mathbf{8 6 . 4}$ \\
Regular & 14 & 13.6 \\
irregular & 45 & 43.6 \\
\hline Duration of abuse: & 58 & $\mathbf{5 6 . 4}$ \\
Less than one year & & \\
One year or more & & \\
& & \\
\hline
\end{tabular}

Kersh: street name for hashish weight $n=$ number of patients

Table (3): ANOVA one way and LSD statistical analysis of the body weight (g), testicular weight (gm), relative testicular weight (gm), lutenizing hormone $(\mathrm{LH})(\mathrm{pg} / \mathrm{ml})$ and testosterone (ng/d) in different studied groups:

\begin{tabular}{|c|c|c|c|c|c|}
\hline $\mathrm{C}^{-}$Group & $\begin{array}{c}\text { Group I } \\
\text {-ve control }\end{array}$ & $\begin{array}{l}\text { Group III } \\
\text { tramadol }\end{array}$ & $\begin{array}{l}\text { Group IV } \\
\text { hashish }\end{array}$ & $\begin{array}{c}\text { Group V } \\
\text { tramadol+ } \\
\text { hashish } \\
\end{array}$ & $\mathbf{P}^{*}$ \\
\hline Parameter & $n=10$ & $n=10$ & $\mathbf{n}=\mathbf{1 0}$ & $n=8$ & \\
\hline Body weight (gm) & $81.3 \pm 8.43$ & $64.6 \pm 6.99^{a}$ & $87.9 \pm 7.98$ & $74.5 \pm 5.27^{b}$ & $<0.001$ \\
\hline Testicular weight (gm) & $0.484 \pm 0.32$ & $0.260 \pm 0.20$ & $0.200 \pm 0.09^{c}$ & $0.99 \pm 0.09^{d}$ & $<0.001$ \\
\hline Relative testicular weight (gm) & $0.62 \pm 0.10^{\mathrm{e}}$ & $0.54 \pm 0.10^{f}$ & $0.20 \pm 0.05$ & $0.12 \pm 0.01$ & $<0.001$ \\
\hline LH (pg/ml) & $3.07 \pm 0.20^{g}$ & $1.92 \pm 0.31$ & $2.02 \pm 0.20$ & $0.88 \pm 0.01^{\text {h\&i }}$ & $<0.001$ \\
\hline Testosterone(ng/dl) & $1.09 \pm 0.31^{j}$ & $0.70 \pm 0.03$ & $0.72 \pm 0.05$ & $0.43 \pm 0.03^{k}$ & $<0.001$ \\
\hline
\end{tabular}

n:number of rats gm:gram pg:picogram ng:nanogram ml:milliliter dl:deciliter Analysis of variance test (ANOVA). ${ }^{*} \boldsymbol{P}<0.05$ : significant .Least significant difference (LSD). $\boldsymbol{P}<\mathbf{0 . 0 5}$ significant, ${ }^{\boldsymbol{a}} \boldsymbol{P}<0.001$ vs - ve control \& hashish groups, ${ }^{\boldsymbol{b}}$ $P<0.05$ vs tramadol \&hashish groups, ${ }^{c} P<0.05$ vs - ve control, ${ }^{d} P<0.001 v s-v e$ control, tramadol \& hashish groups, ${ }^{e} P<0.001$ vs hashish \& tramadol+hashish groups, ${ }^{f} \mathrm{P}<0.001$ vs hashish \& tramadol+hashish groups, ${ }^{g} \mathrm{P}<0.001$ vs tramadol \& hashish groups, ${ }^{h} P<0.05$ vs -ve control group, ${ }^{I} P<0.001$ vs tramadol \& hashish groups, ${ }^{j} P<0.001$ vs tramadol, hashish \& tramadol+hashish groups and ${ }^{k} P<0.05$ vs tramadol \& hashish groups. 
Table (4): Chi square for trend statistical analysis of scoring of degenerative changes and its percentage in different studied group.

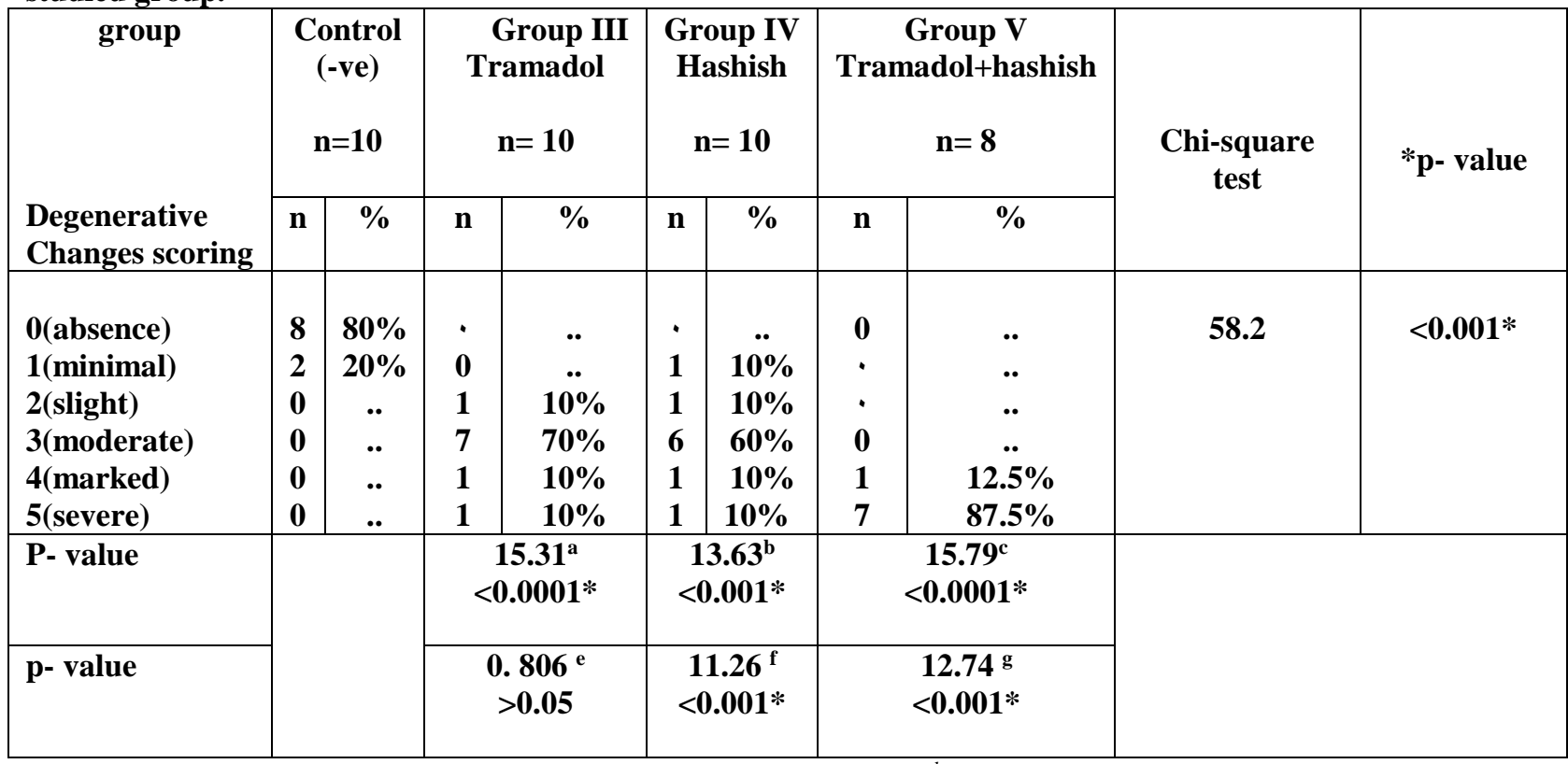

\%: percentage ${ }^{*}$ significant difference ${ }^{a}$ control vs tramadol group, ${ }^{b}$ control vs hashish group ${ }^{c}$ control vs group $V$ ${ }^{e}$ tramadol group vs hashish, ${ }^{f}$ hashish group vs group $V,{ }^{g}$ tramadol vs group $V \quad n=$ number of rats. Scoring according to percentage of tubules affected: Score (0) absence of degeneration, score (1) minimal : fewer than 5\%, score (2) slight: $5 \%-$ $25 \%$, score (3) moderate: $25 \%-50 \%$,score (4) marked: $50 \%-75 \%$, score (5) severe : more than $75 \%$.

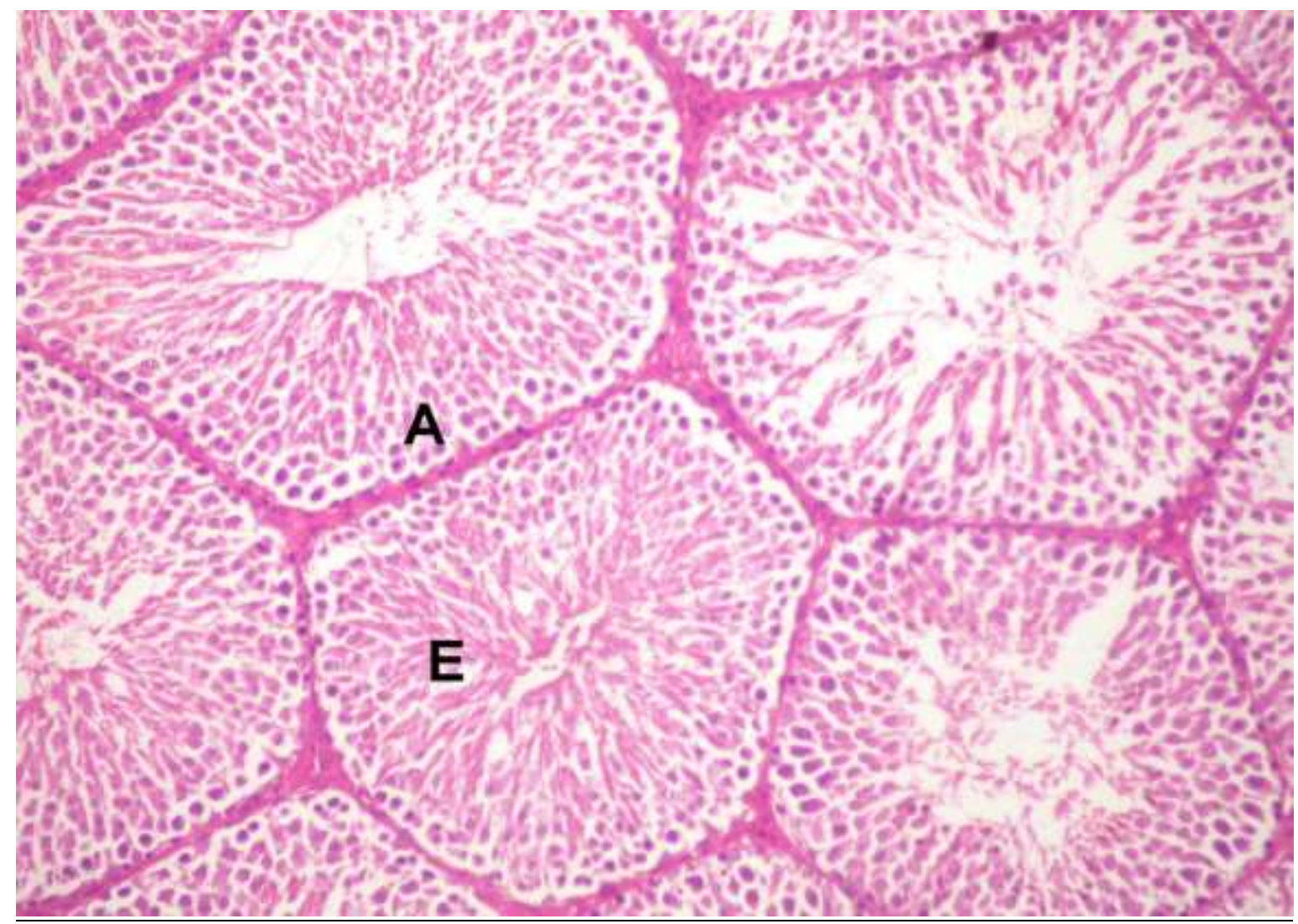

Fig (1): A Photomicrograph of a section in testis of albino rat from control group showing normal seminephrous tubules lined by intact stratified germinal epithelium (E) with patent lumen and aggregated sperms (A) (H\&E x200). 


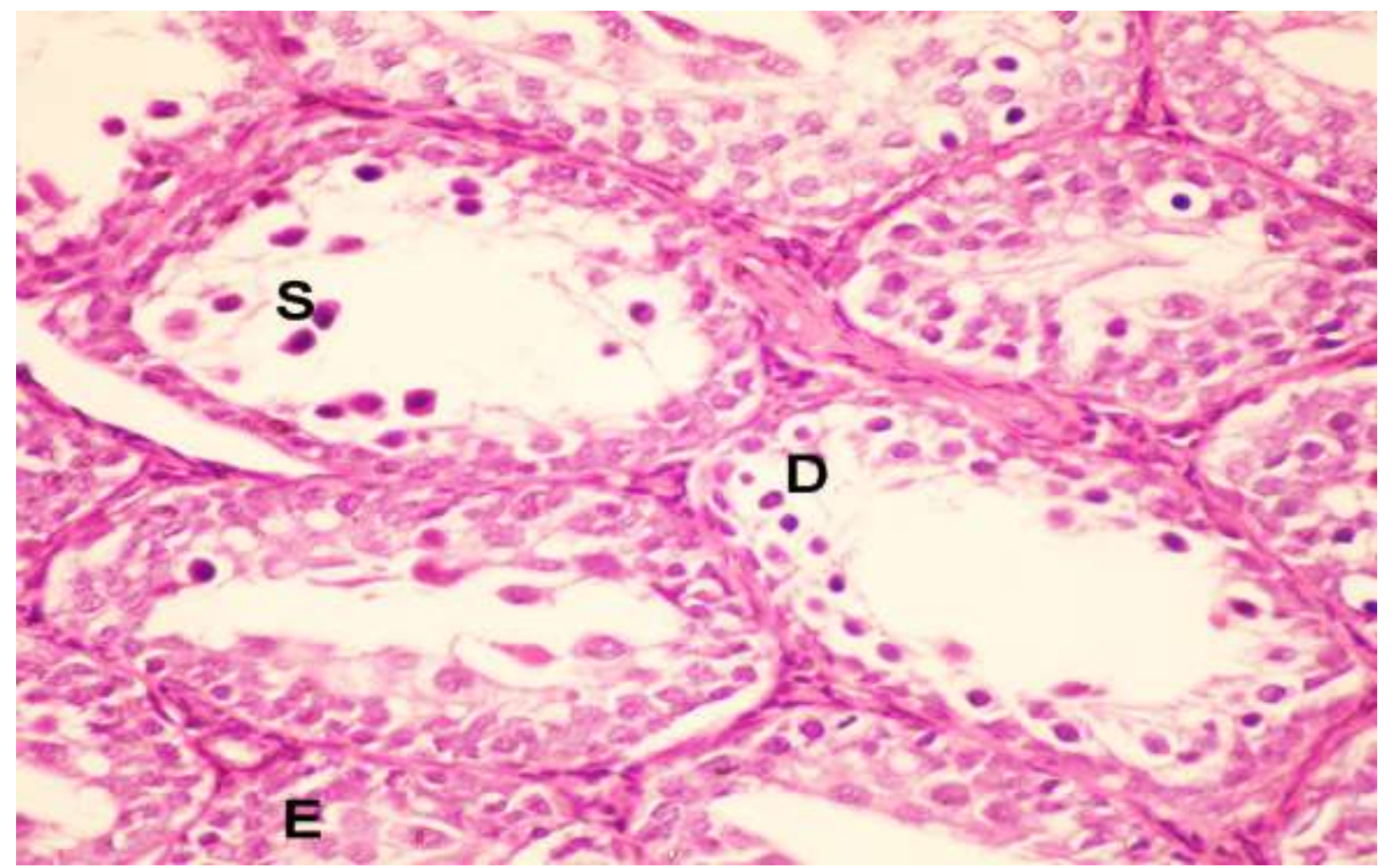

Fig (2): photomicrographs of sections in testes of albino rats from group III (tramadol) showing moderate degenerative changes in seminephrous tubules (D) with sloughing of some epithelial cells in lumen (S). The rest of the epithelial cells are well organized (E) (H\&Ex400)

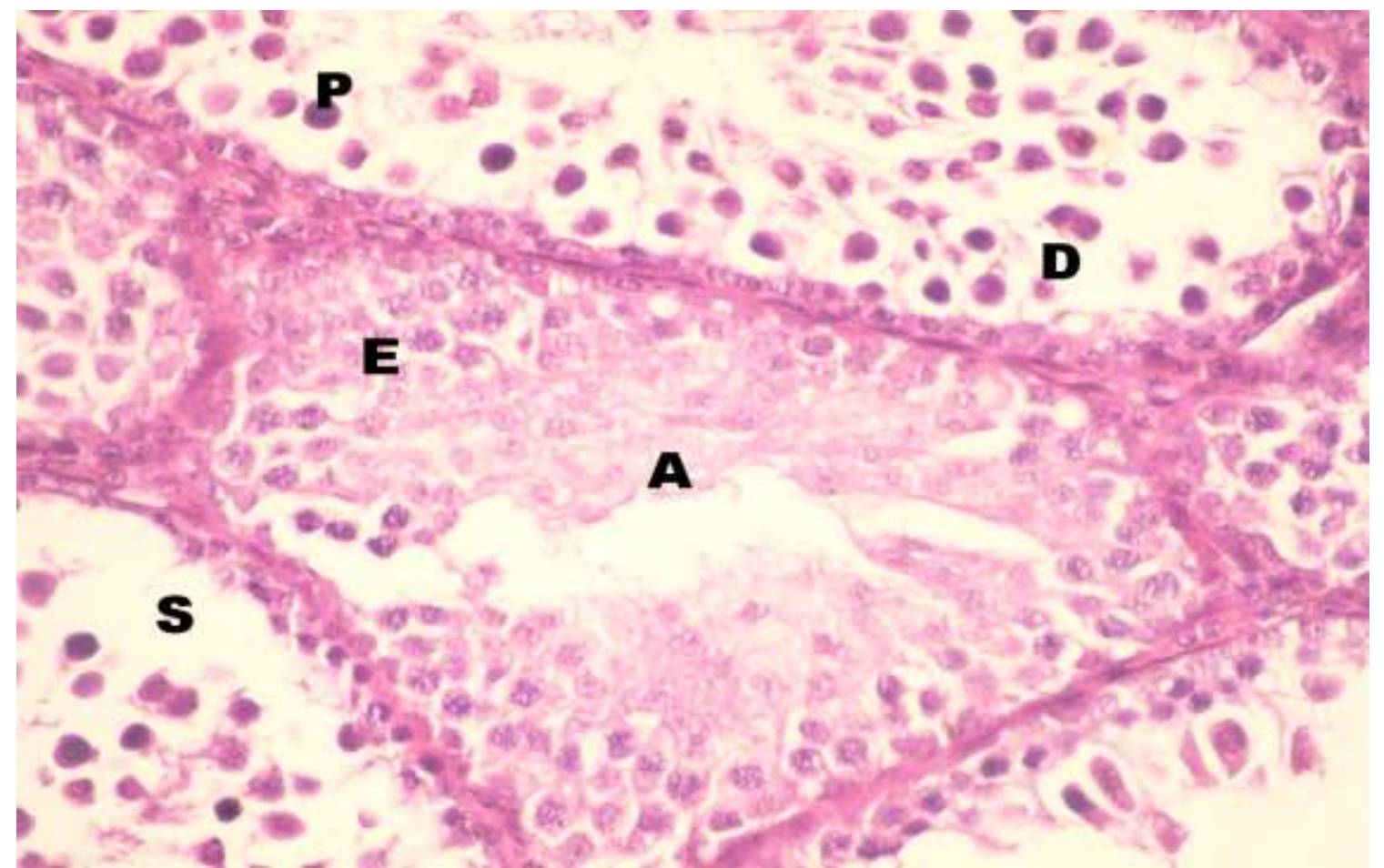

Fig (3): photomicrographs of sections in testes of albino rats from group IV (hashish) showing degenerative changes in some seminephrous tubules (D) with pyknotic nuclei (P), disorganization and sloughing of epithelial cells (S). Other tubules show normal structure with intact basal lamina and well organized epithelial cells (E) and aggregated sperms (A) (H\&Ex400) 


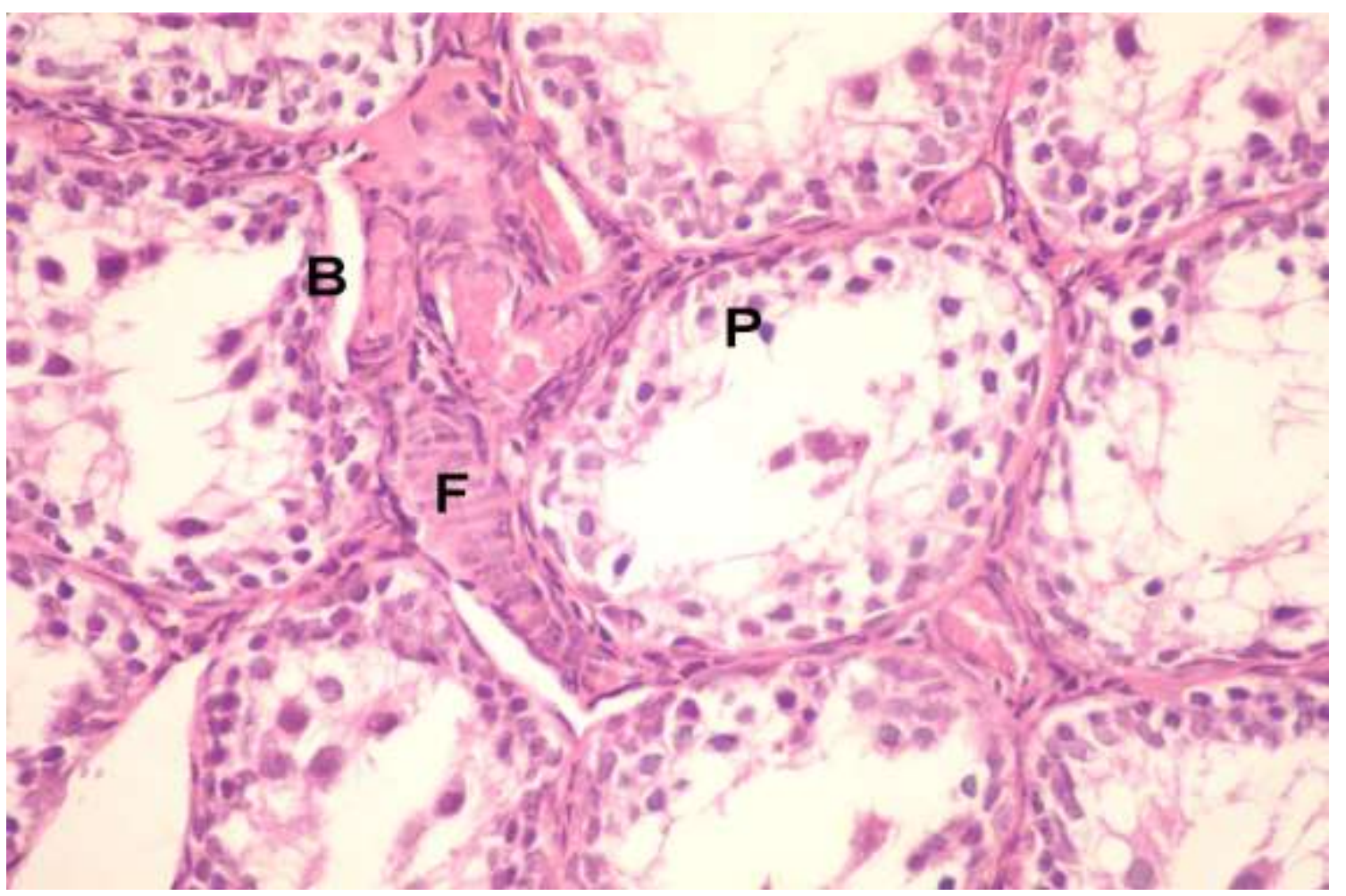

Fig (4): photomicrographs of sections in testes of albino rats from group $V$ (tramadol+hashish) showing pyknotic nuclei (P) and separation of epithelial cells of seminephrous tubules with interstitial fibrosis (F) and separation of basal lamina (B). (H\&Ex400).

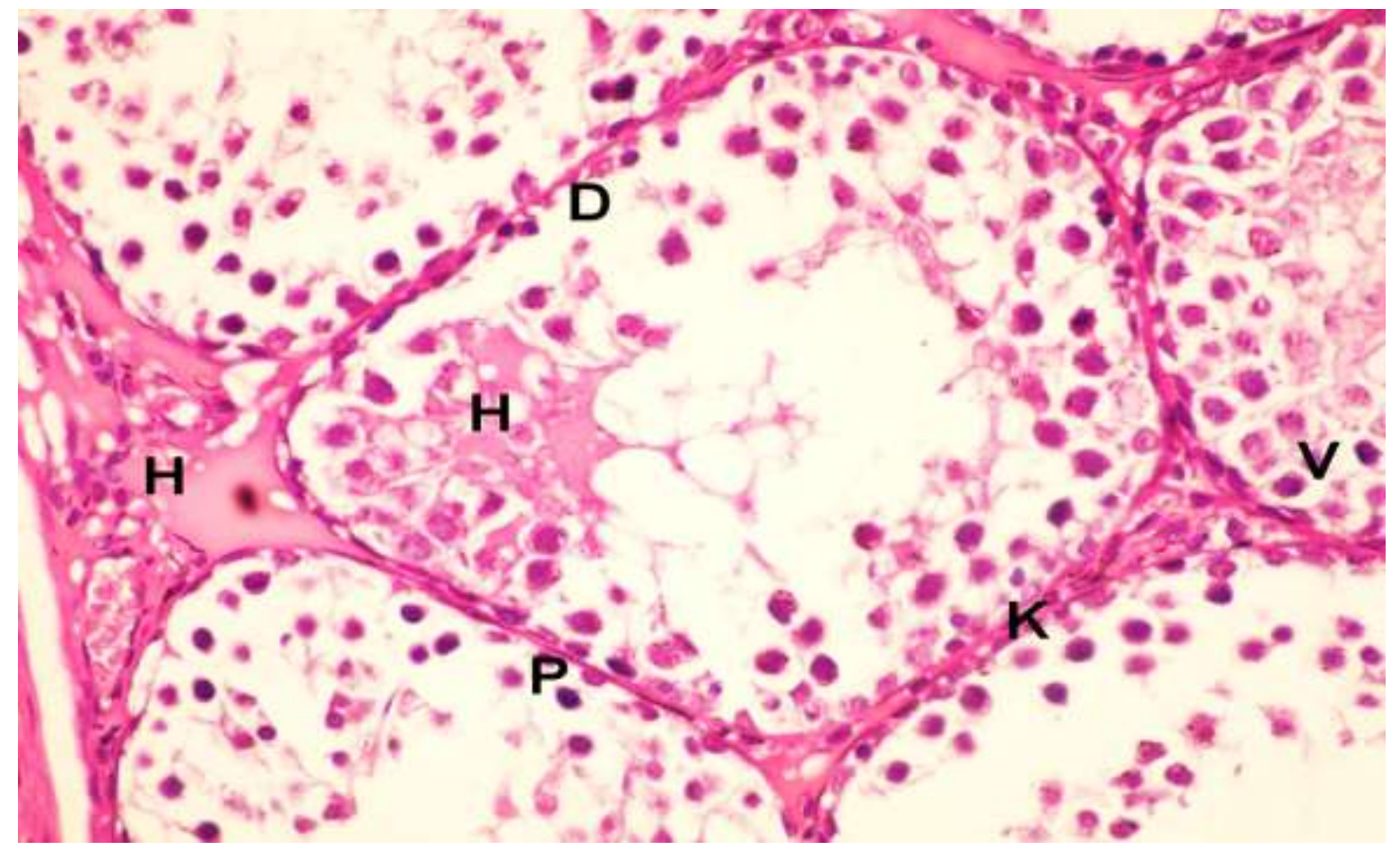

Fig (5): photomicrographs of sections in testes of albino rats from group $\mathrm{V}$ (tramadol+hashish) showing severe degenerative seminephrous tubules (D) with separation of epithelial cells of seminephrous tubules. No aggregated sperms seen in the lumen, hyalinization between and inside seminephrous tubules $(\mathrm{H})$, vaculation (V) and separation of epithelial cells with pyknosis (P) and karyolysis (K) (H\&Ex400). 


\section{Discussion}

Substance abuse is one of the growing public health and social problem that has adversely affected a significant proportion of the population, most of them at adolescence stage (Rowe, 2012).

This study was conducted throughout 2 phases; the first was a cross-sectional study among high schools male students at Zagazig district to find out the point prevalence of drug abuse. The second was experimental on male albino rats to clarify the toxic effects of the most prevalent abused drugs found in the first stage on the reproductive system.

This study revealed that the overall point prevalence of drug abuse among secondary school students was $13.6 \%$. This percent was higher than that reported by Mohamed and Amira (2014) who found that total prevalence of substance abuse among preparatory and secondary schools students was $8.8 \%$. This increase can be supported by the report of WHO regional office of Eastern Mediterranean which declared that drug abuse tends to increase in many regional countries including Egypt among individuals with age 15-24. This may be due to the geographical location and connection to the 3 continents plus the cultivation problem of the addicting plants in Egypt together with political instability and insecurity which give the chance for the well-organized smuggling gangs (Noha et al., 2015).

In this study; most of drug abusers were urban residents. These results may be explained by the availability of drugs in urban communities in addition to the nature of urban residence where most of youth have more contact with peers and less family supervision. These results are in agreement with Donnermeyer and Scheer (2001) who reported that adolescent drug use was more likely in urban and town residents rather than farmdwelling youths. Other studies as Lambert et al., (2008); Aronson et al., (2009) ; Rhew et al., (2011) suggested that youths from more rural residential settings are at higher risk for drug use than those living in urban settings. They explained that limited access to recreational facilities and other community resources in more rural areas could lead to engagement in high-risk behaviors as drug use. However, Zhiwei et al., (2008) found no difference between rural and urban as regards drug abuse.

Regarding social class, this work revealed a higher incidence of drug abuse among students of low and high social classes. These results may be due to the two economic dimensions of either poverty or unemployment which lead to abuse and trafficking drugs in the low social class or the ability to buy those drugs in high social class (Noha et al., 2015). Grunbaum et al., (2000) found a strong association between lower living conditions and drug abuse. In addition, a consistent evidence about the relation between drug use and low social class was noted by Daniel et al., (2009) who explained the results by that most of the low social classes lives in narrow places making the spread of drug use even between the family rapidly, in addition to the stressful living conditions. Moreover, Buchanan (2004) referred the association between low social classes and drug abuse to deprivation and the need of persons in this class to feel better even if this sensation was unreal. Galea et al., (2004) found that low familial socioeconomic status was associated with incident cannabis use. In addition, Dube et al., (2003) noted that lower familial socioeconomic status based on the occupational status of the head of household during the respondent's childhood) was associated with younger age at initiation of drug use. In contrast to all of the above, Bergen et al., (2008) found that use of drugs was not significantly related to any socioeconomic measures.

The average age of the students was $16 \pm 1$.5.The duration of drug abuse in the students was one year or more in $56.4 \%$. This reflects the young age of drug abuse onset. In Egypt, a clear decline in the average age at the beginning of drug abuse was reported in several studies (Noha et al., 2015).

Tramadol was the most common abused drug (50.5\%) followed by combined tramadol and hashish (20.4\%) while hashish abuse represented (14.6\%). These results are in accordance with Mohamed and Amira (2014) who reported that the most common abuse drug among secondary school students was tramadol followed by cannabis. Also, Nabil et al., (2015) found that tramadol abuse was $30.3 \%$ among participants while cannabis was (15.8\%). The higher prevalence of tramadol may be explained by availability in affordable prices with easy access despite being scheduled in Egypt. Besides; most of the students abuse tramadol due to peer pressure, seeking pleasure, belief of escaping from problems at home, or school, improving mood, showing masculinity (El-Sawy et al., 2010) and relieving psychosomatic symptoms related stress (Nabil et al., 2015).

On the contrary; other studies ranked Cannabis as the most abused illicit drug worldwide and in Egypt (NIDA, 2010; Hamdi et al., 2013). However, Ekramy et al., (2015) and Bassiony et al., (2015) showed that tramadol was the commonest drug used among abusers, even exceeding cannabis which was considered in previous studies as the commonest drug of abuse and attributed this to its wide spread medical use as analgesic and the believe that tramadol is not an addictive substance.

In this study, most of the students (86.4\%) abused these drugs regularly and about (56.4\%) abused drugs for one year or more. this reflects seriousness of the problem. In contrast to our results those of Zhang and Liu (2013) and Bassiony et al., (2015) who reported that temporal use of drugs was the most common pattern of use especially among adolescents during examination periods. This discrepancy may be due to differences in the study populations. 
At the end of the clinical study, there were limitations in completing the investigation concerning the toxic effects of the most prevalent abused drug among students because of the incompliance of the students and refusal to continue other tests (blood sampling, radiological imaging or seminal analysis). So, we had to complete the work through an experimental study that included tramadol, hashish \& tramadol+hashish rat groups with equivalent doses and duration to those found in clinical study.

The results of the experimental study revealed a significant reduction in the body weight in tramadol group while in combination of tramadol and hashish it seemed that cannabis obscured the reductive effect of tramadol on body weight.

This can be explained by Grotzkyj-Giorgi (2009) who stated that drug abuse of pain killers, opiates and depressants causes weight loss due to alteration of the diet, irregular eating patterns with severe eating and self-care neglection and poor nutrition. Also, many drug abusers experience digestive problems such as constipation, diarrhea, indigestion and poor appetite.

Moreover, cannabinoids, as well as substances produced within the body that activate cannabinoid receptors (i.e endocannabinoids), exert specific influences on the regulation of feeding behavior stimulation of the CB1 receptors in the mammalian cannabinoid system specifically increases food craving and enjoyment, and promotes the deposition of energy as fat into adipose tissues (Sansone and Sansone, 2014).

In our study, four months administration of tramadol (42 mg/kg/day) or cannabis $(103 \mathrm{mg} / \mathrm{kg} /$ day) caused significant decrease in testicular weight, serum LH \& testosterone. On combining tramadol+hashish administration; a dramatic reduction in the previously mentioned parameters was detected. The histopathological changes detected in H\&E stained sections of adult albino rats' testes from tramadol group or hashish group showed some degenerative changes in seminiphrous tubules with pyknotic nuclei and sloughing of some epithelial cells in the lumen, while in combined tramadol+hashish group there were severe degenerative changes in seminiphrous tubules with pyknotic nuclei and separation of epithelial cells with hyalinization between and inside seminiphrous tubules, interstitial fibrosis, separation of basal lamina, no aggregated sperms seen in the lumen and some cells show karyolysis. These results indicate a synergistic effect of both on the reproductive process.

Azari et al., (2014) explained that tramadol inhibits the secretion of luteinizing hormone (LH) by acting either on the hypothalamus or directly on the pituitary gland, which leads to reduced serum testosterone levels which in turn reduce the structural and functional integrity of the secondary sex organs.

Also, Abdellatief et al., (2015) reported that after 30 days treatment of tramadol alterations in sex hormonal levels in conjunction with disruption of the normal histological structure of rat testis were detected. This might lead to the risk of male infertility.

Tetra hydro-cannabinol (THC); the psychoactive ingredient of cannabis; was reported to induce block of GnRH release resulting in lowered LH and FSH which is responsible for reduced testosterone production by the Leydig cells of the testis . The decrease in testosterone results in decreased sex organ weight and testicular function (Selma et al., 2015). Although some of the change in organ weight may be due to lowered testosterone production by the Leydig cells of the testis, some of the weight changes may be due to a direct action of THC, and perhaps some of the other non-psychoactive cannabinoids in marijuana, on the tissue themselves (Harclerode, 1984). This explains the highly significant reduction of relative testicular weight in cannabis group when compared with control group since hashish reduced the testicular weight with no effect on body weight.

Also, D'Cruz et al., (2010) reported that cannabis administration of doses $(40,60$ and $80 \mathrm{mg})$ caused damage to the basement membrane, shrinkage of the seminiferous tubules, scanty cytoplasm and shrunken nuclei in the germinal epithelium, and complete arrest of spermatogenesis. These effects were seen to be reversed on withdrawal of the drug for 45 days.

Lotfi et al., (2013) reported that C. sativa extract had no significant impact on testis weight and serum testosterone when given at doses of $(10,50,100 \mathrm{mg})$ for 2 weeks duration. This contrast in results can be explained by the longer duration of cannabis administration for 4 months in our current study.

One of the suggested underlying mechanism of tramadol and cannabis induced reproductive toxicity is oxidative stress (D'Cruz et al. 2010; Abdellatief et al. 2015; Ahmed and kurkar 2014; Heba and Azza, 2015).

Conclusion: Among participated secondary schools adolescents; Most of the drug abusers were from urban communities and with either high or low socioeconomic classes. The most prevalent abused drug were tramadol, hashish or combination of both drugs. These drugs have a structural \& functional disruption on the reproductive system in adolescent period with maximum toxic effect on combination of both tramadol + hashish .

\section{Recommendation}

-Periodic toxicological urine screening for drugs of abuse among adolescents in Egyptian schools should be done to estimate and control the substance abuse problem and its health hazards.

-Health education about increasing problem of drug abuse among adolescent Egyptian students during the critical period of testicular development with empathizing on the toxic impact of multiple drug abuse.

- Improving the national plan for drug abuse control among adolescents is needed.

-Further studies for detection of the underlying mechanisms of tramadol \&hashish induced reproductive toxicity. 


\section{Acknowledgment}

We would like to express our gratitude to $\mathrm{dr}$ Heba Elnegres; assistant professor of histology \&cell biology for her effort in histopathological section in this work.

Conflict of interest

The authors declared that there is no conflict of interest

Author's contribution

All authors contributed equally to this work.

\section{References}

Abdellatief RB, Elgamal DA and Mohamed EE (2015): Effects of chronic tramadol administration on testicular tissue in rats: an experimental study. Andrologia. 47(6):674-9

Ahmed MA and Kurkar A (2014): Effects of opioid (tramadol) treatment on testicular functions in adult male rats: The role of nitric oxide and oxidative stress. Clin Exp Pharmacol Physiol. 41(4):317-23

Aronson KR, Feinberg ME and Kozlowski L (2009): Alcohol, tobacco, and other drug use among youth in rural Pennsylvania. Harrisburg, PA: center for rural Pennsylvania

Azari O, Emadi L, Kheirandish R et al., (2014): The effects of long-term administration of tramadol on epididymal sperm quality and testicular tissue in mice. Iranian J. of Veteran. Surg. 9(1):23-9.

Bancroft JD and Gamble M (2002):Theory and practice of histological technique. 5th edition. Edinburg and London: Churchill Livingstone.

Bassiony MM , SalahELdeen GM, Youssef U et al., (2015): Adolescent tramadol use and abuse in Egypt. Am. J. Drug Alcohol Abuse. 41(3): 20611.

Bergen SE, Gardner CO, Aggen SH et al., (2008): Socioeconomic status and social support following illicit drug use: causal pathways or common liability? Twin Res Hum Genet. 11(3):266-74.

Buchanan J (2004): Missing links? Problem drug use and social exclusion. Probation J. 51(4):387-97.

D'Cruz SC, Vaithinathan S, Jubendradass $\mathrm{R}$ et al., (2010): Effects of plants and plant products on the testis. Asian J. Androl. 12 (4):468-79.

Daniel JZ, Hickman M, Macleod J et al., (2009): Is socioeconomic status in early life associated with drug use? A systematic review of the evidence. Drug Alcohol Rev. 28(2):142-53.

Donnermeyer JF and Scheer SD (2001): An analysis of substance use among adolescents from smaller places. J. Rural Health. 17 (2):105-113.

Dube SR, Felitti VJ, Dong M et al., (2003): Childhood abuse, neglect, and household dysfunction and the risk of illicit drug use: the adverse childhood experiences study. Pediatrics. 111(3):564-72
Ekramy E, Mohamed M, Mostafa A et al., (2015): Liver functions derangement among substances abusers. Int. J. Med. Phar. Sci. 6 (3):19-26

El-Sawy H, Hay MA and Badawy A (2010): Gender differences in risks and pattern of drug abuse in Egypt. Egypt J. Neurol. Psychiatry Neurosurg. 47(3):413-18.

Fronczak CM, Kim ED and Barqawi AB (2012): The insults of illicit drug use on male fertility. J. Androl. 33 (4):515-28.

Galea S, Nandi A and Vlahov D (2004): The social epidemiology of substance use. Epidemiol. Rev. 26:36-52.

Grotzkyj-Giorgi M (2009): Nutrition and addiction: can dietary changes assist with recovery? Drugs and Alcohol Today. 9: 24-8.

Grunbaum JA, Tortolero S, Weller N et al., (2000): Cultural, social, and intrapersonal factors associated with substance use among alternative high school students. Addict Behav. 25:145-51

Hamdi E, Gawad T, Khoweiled A et al., (2013): Lifetime prevalence of alcohol and substance use in Egypt: a community survey. Subst Abus; 34(2):97-104.

Harclerode J. (1984): Endocrine effects of marijuana in the male: preclinical studies. NIDA Res Monogr. 44:46-64.

Heba Y and Azza H (2015): Histopathological and biochemical effects of acute and chronic tramadol drug toxicity on liver, kidney and testicular Function in adult male albino rats. J. Med. Toxicol \& Clin Forensic Med. 1(2): 1-7.

Knight JR, Harris SK, Sherritt L et al., (2007): Prevalence of positive substance abuse screen results among adolescent primary care patients. Arch. Pediatr. Adolesc. Med. 161(11):1035-41.

Kronfol NM (2012): Historical development of health professions' education in the Arab world. East Mediterr Heal J. 18(11):1157-65.

Lambert D, Gale JA and Hartley D (2008): Substance abuse by youth and young adults in rural America. J. Rural Health. 24 (3):221-28.

Lanning LL, Creasy DM, Chapin, RE et al., (2002): Recommended approaches for the evaluation of testicular and epididymal toxicity. Toxicol. Pathol. 30:507-20.

Lotfi N, Khazaei M, Mohamed S et al., (2013): The effect of cannabis sativa hydroalcoholic extract on sperm parameters and testis histology in rats. Int. J. Morphol. 31(1):82-86.

Miller JW, Naimi TS, Brewer RD et al., (2007): Binge drinking and associated health risk behaviors among high school students. Pediatrics. 119(1):76-85.

Miras C, Kephalas T and Papadakis D (1971): The effect of hashish extract on the norepinephrine in rabbit brain. Bull Narcot. 23:33-4. 
Mohamed GN and Amira AF (2014): Prevalence of substance abuse among adolescent school students in Zagazig. Egyptian J. of psychiatry. 35(3): 161-66.

Nabil R, Lamia G, Amro S et al., (2015): An epidemiological study of tramadol $\mathrm{HCl}$ dependence in an outpatient addiction clinic at Heliopolis Psychiatric Hospital. Menoufia Medical J. 28:591-96.

National Institute of Drug Abuse (2010): Drug, brains, and behavior. The science of addiction. NIDA: $1-144$. DOI: http://www.drugabuse.gov/sites/default/files/sci ofaddiction.pdf. Available at: www.nida.nih.gov/infofacts/khat.html. [17 April 2016].

Noha AS, Menn A, Albert ES et al., (2015): Rates of use and addiction of drugs and alcohols. Collective report for stages of National research of addiction. Research unit. General Secretariat for mental health and addiction treatment. Ministry of health and Population Egypt: 9-33. Available from: http://mentalhealthegypt.com/ pdf/

Quinn R (2005): Comparing rat's to human's age: How old is my rat in people years? Nutrition; 21:7757

Reagan-Shaw S, Nihal M and Ahmad N (2008): Dose translation from animal to human studies revisited. FASEB J. 22(3):659-61.

Rhew IC, David Hawkins J and Oesterle S (2011): Drug use and risk among youth in different rural contexts. Health and Place. 17(3):775-83.
Rowe CL (2012): Family Therapy for Drug Abuse: Review and Updates 2003-2010. J. Marital and Family Therapy. 38(1): 59-81.

Sansone RA and Sansone LA (2014): Marijuana and body weight. Innov Clin Neurosci. 11(7-8):50 4.

Selma S, Gad Allah M, Shereen F et al., (2015): Assessment of Serum Thyroid profile concentration among Sudanese Marijuana abuse People. Sch. Bull. 1(6): 151-53.

Sengupta P (2012): A Scientific Review of Age Determination for a Laboratory Rat: How old is it in comparison with Human age? Biomed Int. 2012; 2:81-9.

Sharma A, Fish BL, Moulder JE et al., (2014): Safety and blood sample volume and quality of a refined retro-orbital bleeding technique in rats using a lateral approach. Lab. Anim. (NY). 43 (2):63-6.

Zhang $\mathrm{H}$ and Liu Z (2013): The investigation of tramadol dependence with no history of substance abuse: A cross-sectional survey of spontaneously reported cases in Guangzhou City, China. Biomed. Res. Int. 1-6.

Zhiwei Z, Alycia I, Michael M et al., (2008): An analysis of mental health and substance abuse disparities \& access to treatment services in the appalachian region. Appalachian Regional Commission. Available at: www.arc.gov or www.norc.org . [20 August 2016]. 


\section{الملخص العربيى}

\section{التأثيرات السمية لأكثرالعقاقير المخدرة انتثارا بين طلاب بعض المدارس الثانوية المصرية على الجهاز التناسلي دراسة اكلينيكية وتجريبة المبرابة}

\section{أميمة ابراهيم عبد الحميد ويارا محمد الفخراني' وأميرة السيد عبد السلام’}

تعد ظاهرة تعاطي المخدر ات بين المر اهقين مشكلة طبية واجتماعية متزايدة في مصر خاصة مع نقاد القص المعلومات المتعلقة

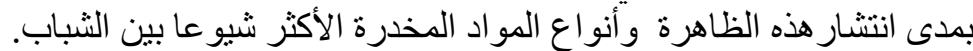

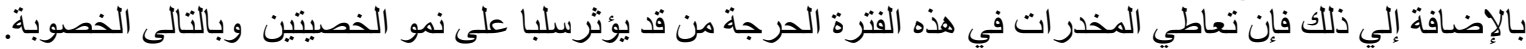

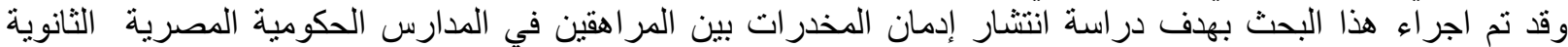

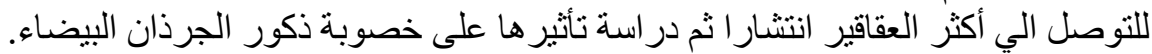

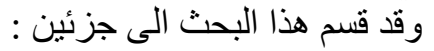

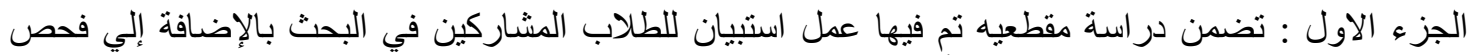

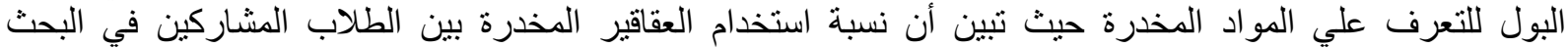

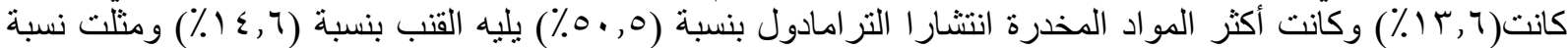

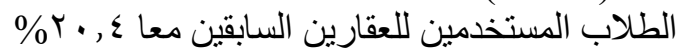

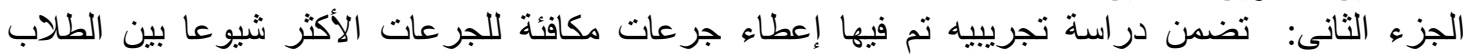

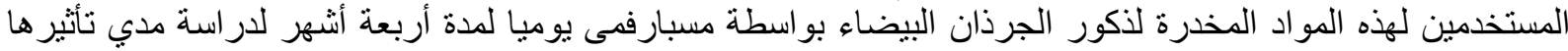

$$
\text { وقد تبين حدوث الجهاز التناسلي }
$$

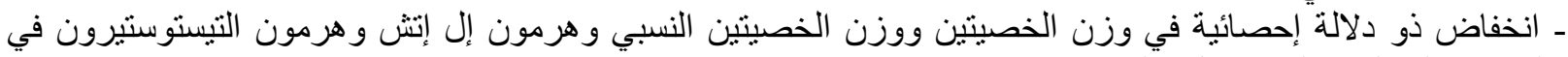

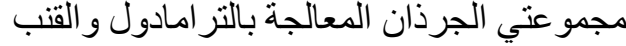
ـ انخفاض شديد في كل الدلالات السابقة في المجمو عة التى تم اعطائها عقار التر امادول و القتب معا.

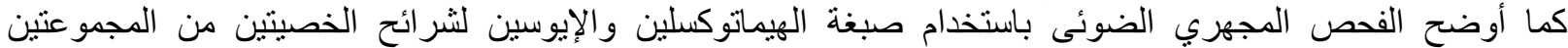

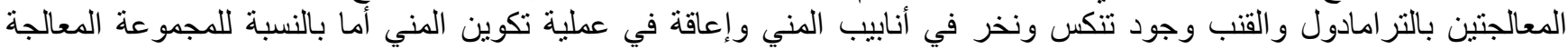

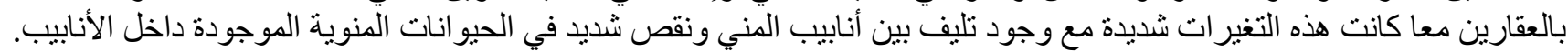

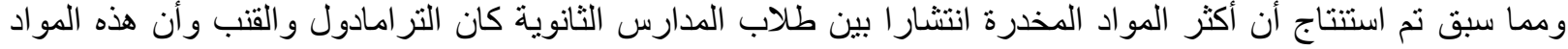

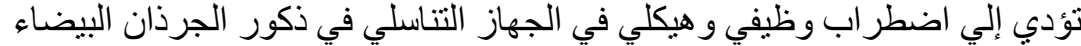

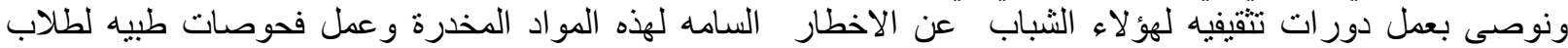
المدارس تثتمل على تحاليل المخدر ات وتحاليل الخصوبة. 